\title{
ESTUDIO DE UNA PROVINCIA: MARACAIBO, SIGLO XVIII
}

\author{
MaríaDolores Fuentes Bajo \\ UNIVERSIDAD DE CÁdIZ
}

\section{RESUMEN}

La investigación que presentamos se ocupa de un personaje concreto y de sus peripecias en un contexto bastante definido; se trata de Francisco de Ugarte, un marino guipuzcoano que fue gobernador de Maracaibo, mediado el siglo XVIII. La accidentada vida de este militar en sus años venezolanos ha servido de excusa, también, para analizar la realidad de la provincia de Mérida-Maracaibo en este periodo. Las tensiones que se recogen en los expedientes consultados no son algo aislado, sino que guardan relación con una problemática más general.

Venezuela se debate en el siglo XVIII entre la tradición y la modernidad. Dividida hasta entonces en un mosaico de gobernaciones sin relación entre sí, la política de los Borbones pretenderá realizar ambiciosas remodelaciones en orden a articular estas diversas regiones. No obstante, se trata de un proceso laborioso; la nueva andadura que se propone emprender deberá hacer frente a no pocos desajustes y tensiones en el seno de las mismas provincias y entre unas y otras, lo que determinará, en buena medida, que el ritmo de estas transformaciones sea más lento que el deseado

Palabras Clave: Venezuela, Maracaibo, siglo XVIII, gobernador Francisco de Ugarte.

\section{ABSTRACT}

The research that we are presenting here is about a particular character and his unexpected events in a quite concrete context; it is about Francisco de Ugarte, a sailor from Guipúzcoa (north of Spain), who was governor of Maracaibo, about the middle of the $18^{\text {th }}$ century. The eventful life of this soldier in his Venezuelan years has been also an excuse, to analyze the reality of the Province of Merida-Maracaibo in this period. The pressures gathered in the conferred briefs are not something isolated, yet they are related to more general problems.

Venezuela struggles between tradition and modernity in the $18^{\text {th }}$ century. Venezuela had been divided until then in several "gobernaciones" without relationship; the Borbons" policy will try to accomplish ambicious changes in order to connect these varied regions. Nevertheless the process will be laborious; the new walking which they set will face many 
disagreements and pressures, within the provinces and among them, all this will make, in some way, that the rhythm of these transformations will be slower than thought.

Key words: Venezuela, Maracaibo, $18^{\text {th }}$ century, Governor Francisco de Ugarte

Toda investigación significa un reto para el estudioso; ésta no ha sido una excepción. Las vicisitudes del gobernador Ugarte han sido reconstruidas, en gran medida, gracias a sus propios escritos ${ }^{1}$; en ellos se presenta a Ugarte en circunstancias muy diversas: unas veces, gracias al respaldo de Madrid -en concreto, del marqués de Ensenada- muy seguro de sí mismo; otras, cronológicamente posteriores, aparece vacilante, al sentirse injustamente perseguido y, peor aún, abandonado por sus mecenas. Francisco de Ugarte nos va a referir fundamentalmente su verdad, como es lógico; el construye su propia biografía, moldeándola en cada momento según sus intereses. Esta modalidad de fuente escrita en primera persona requiere un análisis especial, como bien ha señalado James Amelang, más si se trata de figuras como la de Ugarte, protagonista y víctima al mismo tiempo de estos agitados años que se viven en la gobernación de Maracaibo $^{2}$.

\section{A PROPÓSITO DE MARACAIBO}

Había nacido la provincia de Maracaibo a finales del siglo XVI; se la reseña en las fuentes con diversos nombres, a medida que al territorio inicial se van agregando otras circunscripciones; se la denomina así "gobernación del Espíritu Santo de La Grita”, en 1572, “corregimiento de Mérida-La Grita” algún tiempo después (1608) y , por último, "provincia de Mérida, La Grita y ciudad de Maracaibo", en documentos fechados con posterioridad a $1676^{3}$.

La provincia de Maracaibo era una más de las gobernaciones desperdigadas por Tierra Firme -al lado de Cumaná, Trinidad, Margarita, Venezuela y Guayana-. A lo largo del siglo XVIII -sobre todo en sus décadas finales- se operarán de forma paulatina transformaciones significativas encaminadas a integrar- $y$, en gran medida, rentabilizar- las diferentes provincias, al tiempo que cada vez tendrá más peso una de ellas, la de Venezuela, y su capital, Santiago de León de Caracas. En este proceso serán hitos importantes la aparición de la Intendencia, la Audiencia y, sin duda, el Real Consulado, así como la elevación del obispado de Caracas al rango de arzobispado ${ }^{4}$.

\footnotetext{
Los documentos consultados para este trabajo proceden del Archivo General de Indias de Sevilla, así como de diferentes archivos gaditanos (Archivo de la Catedral y Archivo Diocesano).

2 "Formas de escritura popular: las autobiografías de artesanos". En Antonio CASTILLO (comp.), Escribir y leer en el siglo de Cervantes. Barcelona, Gedisa editorial, 1999, pp. 129-142.

3 Guillermo MORÓN, Breve historia de Venezuela. Madrid, Espasa-Calpe, S.A., 1979, pp.106ss. ; Germán CARDOZO GALUE, Maracaibo y su región histórica. Maracaibo, 1983; Belín VÁZQUEZ DE FERRER, "Maracaibo y su espacio histórico. S. XVIII", En: Tierra Firme. Revista de Historia y Ciencias Sociales, 3, III, pp. 215-236 (1985); Enrique NÓBREGA, "Notas sobre la élite militar en la provincia de Maracaibo: 1750-1814". En Carmen MENA GARCÍA, Venezuela en el Siglo de las Luces. Sevilla-Bogotá 1995, pp. 255ss.; Ileana PARRA GRAZZINA, Proceso de formación de la provincia de Mérida, La Grita y ciudad de Maracaibo, 1574. 1676. Tesis Doctoral dirigida por Francisco Morales Padrón. Ejemplar mecanografiado de la Escuela de Estudios Hispano-Americanos de Sevilla. Sevilla, 1984.

4 John V. LOMBARDI, Venezuela. La búsqueda del orden. El sueño del progreso. Barcelona, Editorial Crítica, 1985, pp. 107ss.; Antonio ARELLANO MORENO, Breve historia de Venezuela, 1492-1958. Caracas, Italgráfica,
} 
Sin embargo, en los años en que se fechan los turbulentos sucesos que le tocó vivir a Francisco de Ugarte, estas remodelaciones aún no habían concluido. Desde el punto de vista administrativo, la organización de Maracaibo era todavía bastante compleja, pues estaba vinculada tanto a Caracas como a Santa Fe de Bogotá, dos capitales demasiado distantes y distintas como para abordar una política común. En este sentido, sirva de ejemplo que Maracaibo formó parte hasta los años 80 del siglo XVIII del obispado de Caracas 5 , aunque la iglesia metropolitana estaba en Santa Fe de Bogotá; en lo que se refiere a los complicados negocios de la política, podía oír el parecer del gobernador de Caracas, si bien en última instancia tenía que acatar las resoluciones del virrey y la Audiencia de Santa Fe.

Maracaibo además, por estas décadas, no acababa de despegar a causa de problemas de la más variada índole. Los indios motilones constituían para la región una de sus mayores preocupaciones. Los devastadores efectos de sus incursiones provocaban una situación de alerta continua; las haciendas se resentían de sus periódicos asaltos, al igual que los caminos, siendo una constante el elevado número de muertos. Pero lo que más intranquilizaba a la población era el convencimiento de que se trataba de una cuestión difícil sino imposible de resolver ${ }^{6}$ Francisco de Ugarte, al poco tiempo casi de tomar las riendas del gobierno, presentó un proyecto mediante el que pretendió dar su parecer sobre tan grave materia así como sugerir posibles remedios ${ }^{7}$.

S.R.L., 1974, pp.72ss. ; Miquel IZARD, Tierra Firme. Historia de Venezuela y Colombia. Madrid, Alianza Editorial, 1987, pp. 41ss.; Guillermo MORÓN, El proceso de integración de Venezuela (1776-1793). Caracas, Academia Nacional de la Historia, 1987.

5 En 1784 nació el obispado de Mérida-Maracaibo. La génesis de esta diócesis fue larga atendiendo a que había sido aprobada siete años antes; en parte influyeron las tensiones entre Coro, Mérida y Maracaibo por ser la sede del nuevo obispado. Pueden consultarse el estudio ya clásico de Odilo GÓMEZ PARENTE sobre el primer obispo de Mérida (Ilustrísimo padre fray Juan Ramos de Lora: fundador de la Universidad de los Andes. Caracas, Universidad Católica “Andrés Bello", Instituto de Investigaciones Históricas, 1974) y un trabajo mío titulado "La justicia de un obispo. Los difíciles comienzos de la diócesis de Mérida-Maracaibo, 1784-1790”. En: Procesos Históricos IV, 7, enero 2005.

6 En una comunicación presentada al Primer Congreso Sudamericano de Historia de Santa Cruz de la Sierra, Bolivia, celebrado del 20 al 22 de agosto de 2003, estudié las dificultades sufridas en la población de Gibraltar a causa de la vecindad de los indios motilones ("Entre poderosos anda el juego. Visitadores versus gobernantes. Gibraltar, Venezuela, 1749-1752”. En prensa).

7 Representación de Francisco de Ugarte al marqués de Ensenada adjuntando proyecto. Maracaibo 8 de noviembre de 1753 (Archivo General de Indias de Sevilla, AGI, Caracas, legajo 144). Véase también una carta del gobernador Ugarte, de Maracaibo 30 de diciembre de 1753, que se guarda en el mismo legajo Fueron los capuchinos los que se preocuparon más por la evangelización de los motilones, aunque fue una tarea difícil y casi siempre descorazonadora. Su misión en Maracaibo se fecha entre 1694 y 1818 y ha sido estudiada por Buenaventura DE CARROCERA ("Memoria sobre las misiones de los padres capuchinos". En Memoria del Primer Congreso Venezolano de Historia Eclesiástica. Maracaibo 5 al 8 de noviembre de 1969. Caracas, Italgráfica S.R.L., 1970, pp. 71ss. Del mismo autor, "La cristianización de Venezuela durante el periodo hispánico". En Memoria del Segundo Congreso Venezolano de Historia Eclesiástica. San Cristóbal 13 al 18 de noviembre de 1972. Caracas, Editorial Arte, 1975, pp. 189ss.). Sobre las diversas políticas indígenas en zonas de frontera existe una amplia bibliografía. Destacaríamos algunos trabajos, como los de Pablo Nidal PALMAR PAZ ("Resistencia y aniquilación del pueblo Añú en la época colonial". En Pueblos y culturas de la cuenca del lago de Maracaibo. Editado por la Comisión V Centenario del Lago de Maracaibo. Maracaibo, 2001), Philip W. POWELL (La guerra chichimeca, 1550-1600. México, Fondo de Cultura Económica, 1977), Álvaro JARA (Guerra y sociedad en Chile. Santiago de Chile, Editorial Universitaria, 1987) y Alberto GULLÓN ABAO ("Los jesuitas en la frontera este de la gobernación de Tucumán". En Estudios de la Universidad de Cádiz ofrecidos a la memoria del profesor Braulio Justel Calabozo. Edición de Javier MARTÍN CASTELLANOS, Fernando VELÁZQUEZ BASANTA, Joaquín BUSTAMANTE COSTA. Cádiz, Universidad, 1998, pp. 547ss.). 
Las fuentes denuncian, en otro orden de ideas, los limitados recursos económicos de la provincia, problema en cierta medida derivado del anterior. Las principales actividades económicas de la zona eran las agrícolas, documentándose diferentes haciendas y estancias - no muchas ni muy grandes- destinadas en su mayoría al cultivo del cacao y del tabaco. Su rentabilidad era bien modesta, como se señala con insistencia, a causa de la inseguridad que asolaba la región y la esterilidad de la propia tierra.

Se mencionan también intercambios comerciales, aunque fuera de los circuitos legales. El distanciamiento de la provincia de los centros de poder importantes -léase, las malas comunicaciones con Cartagena de Indias- junto al bajo nivel adquisitivo de sus gentes, convertían el contrabando en una de las vías más apropiadas para abastecerse de determinados artículos a un precio moderado. El que fuera virrey de Santa Fe, Sebastián de Eslava, decía de Maracaibo, en este sentido, que era la provincia del virreinato "más relajada". Francisco de Ugarte, nuestro polémico gobernante, emplearía todas sus energías en cortar este "ilícito comercio", lo que le acarreó un número considerable de enemigos ${ }^{9}$.

Debe mencionarse, igualmente, la débil implantación de las instituciones en la gobernación, como otro de los grandes problemas a los que debía enfrentarse Maracaibo. Desde el punto de vista administrativo, la provincia tenía un funcionamiento complejo y bastante ineficaz; los documentos recogen tensiones entre los escasos representantes de la Corona asentados en la zona, a lo que se añadían sus problemáticas relaciones con las autoridades de Santa Fe de Bogotá, de quienes dependían.

Los expedientes estudiados nos muestran una gobernación en muchos momentos convulsa. El enfrentamiento entre los diversos funcionarios llegó a revestir notas de especial gravedad: en Mérida y Barinas, por ejemplo, hubo conflictos de inusitada violencia que determinaron la mediación de autoridades superiores para investigar las muertes que se produjeron, si bien sus resultados fueron limitados al enfrascarse en cuestiones puramente secundarias. En Maracaibo, el propio Francisco de Ugarte tuvo roces de consideración con su propio teniente y con los oficiales de la Real Hacienda, por no citar sus agrias relaciones con los gobernadores que le sucedieron en el cargo, de los que sufrió represalias y vejaciones de la más variada índole, si atendemos al contenido de sus memoriales.

Rastrear las razones de este fenómeno es complicado, aunque se puede aventurar que estas fricciones, más o menos solapadas pero siempre constantes, apuntan a la existencia de grupos de poder con intereses -económicos, sobre todo-enfrentados; a ello habría que añadir que llegan a ser desmesurados y en eso tiene mucho que ver el contexto en el que ocurren, pues se trata claramente de una sociedad de frontera.

El diferente posicionamiento de los representantes de la Corona guarda relación con lo dicho anteriormente. Tal vez algunos de ellos se sintieran identificados con los intereses locales de Maracaibo, fruto de una larga permanencia en la gobernación o incluso por ser aquella su lugar de nacimiento. Frente a este grupo, otros oficiales reales, recién llegados y con poco o ningún conocimiento de los intereses en juego, propugnarían una polí-

\footnotetext{
Carta de Sebastián Eslava a Francisco de Ugarte, de Santa Fe 3 de noviembre de 1751 (AGI, Caracas, legajo 145). Véase, Antonio García Baquero, La carrera de Indias: suma de la contratación y océano de negocios. Sevilla, Sociedad Estatal para la Exposición Universal Sevilla 92-Algaida Editores S.A., 1992.

9 Auto del gobernador Francisco de Ugarte, de Maracaibo 27 de enero de 1753 (AGI, Caracas, legajo 146); memorial de Ugarte al monarca. Sin fecha, probablemente de 1770 (AGI, Caracas, legajo 145).
} 
tica diferente, acorde con el talante reformista de la monarquía. Creo que puede ser ésta la clave de las dificultades que tuvo que afrontar Francisco de Ugarte en la provincia ${ }^{10}$.

Después de estas pinceladas sobre Maracaibo, en los años centrales del siglo XVIII, la exposición ha de detenerse en aquellos personajes que les tocó vivir nuestra agitada historia.

\section{MARINERO EN TIERRA}

En primer término es obligado mencionar a Francisco de Ugarte, el eje central de este trabajo, una personalidad atractiva y, por supuesto, compleja; su vida, llena de sobresaltos, de algunos momentos de gloria y otros muchos de olvido, merecería la pena inmortalizar en una novela. Nuestra tarea de archivo, en este sentido, no ha podido ser más gratificante; hasta tal punto es cierta esta afirmación que nos resistíamos a ponerle fin, pues cuando suponíamos conocer los entresijos de la existencia de Ugarte, el descubrimiento casual de nuevos episodios nos convencía de la idoneidad de seguir avanzando por otros derroteros.

Contemos de forma ordenada las peripecias de este personaje, en la medida de lo posible. Había nacido en una villa de Guipúzcoa -Idiazabal-, allá por 1706, si bien más tarde decidió afincarse en Cádiz ${ }^{11}$. De 1721 a 1750, es decir durante casi 30 años, sirvió en la armada del rey lo que le obligó a participar en diferentes campañas, en algunos casos, en puestos de responsabilidad $^{12}$. En 1751, fue nombrado gobernador de Maracaibo, premio

10 Carta de Francisco de Ugarte al monarca, de Maracaibo 9 de noviembre de 1754 (AGI, Caracas, legajo 144). Belín VÁZQUEZ DE FERRER y Nereyda FERRER son responsables de un interesante trabajo titulado "Propuesta de análisis y fuentes para el estudio de las redes sociales de poder". En Seminario Hispano-Venezolano. Poder y mentalidad en España e Ibero América. Enrique MARTÍNEZ RUIZ (Coord.). Madrid, Artes Gráficas Milenio, 2000, pp. 15ss. Véase también, Edda SAMUDIO, "La élite capitular de Mérida”. En Emanuele AMODIO, La vida cotidiana en Venezuela durante el siglo XVIII. Maracaibo, Gobernación del Estado Zulia, Secretaría de Cultura, 1998 , pp. 153ss. Sobre los encuentros y desencuentros de los funcionarios del monarca en tierras americanas se han publicado algunos trabajos, como los de Edberto Oscar ACEVEDO ("Controversias legales y humanas en el territorio rioplatense hacia fines del siglo XVIII”. En Entre Puebla de los Ángeles y Sevilla. Homenaje al Dr. J.A. Calderón Quijano. Edición de Ma Justina SARABIA VIEJO, Javier Ortiz DE LA TABLA DUCASSE, Pablo Emilio PÉREZ- MALLAINA BUENO, José Jesús HERNÁNDEZ PALOMO. Sevilla, Escuela de Estudios Hispano-Americanos-Universidad de Sevilla, 1997, pp. 420 ss. ) y Ana BARRERO GARCÍA ("Virreyes versus Audiencias, un conflicto endémico". En Libro homenaje In Memoriam Carlos Díaz Rementería. Editores Gustavo E. PINARD y Antonio MERCHAN. Huelva, Universidad, 1998, pp. 127ss.). Sobre el concepto de frontera y su aplicación a la diversa realidad americana recomiendo la lectura de una colaboración de Alfredo JIMÉNEZ NUÑ̃EZ en el Homenaje al Dr. J.A. Calderón Quijano citado más arriba (La frontera en América: observaciones, críticas y sugerencias, pp. 475ss), así como el trabajo de José Luis CAÑO ORTIGOSA, centrado en el caso de Mérida ("La visita de Vázquez de Cisneros a Mérida: organización de una jurisdicción fronteriza”. En Metodología y nuevas líneas de investigación de la Historia de América. Compiladoras: Emelina MARTÍN ACOSTA, Celia PARCERO TORRE, Adelaida SAGARRA GAMAZO. Burgos, Universidad de Burgos- Asociación Española de Americanistas, 2001, pp. 147ss.)

11 Era hijo de Ignacio de Ugarte y María Estefanía de Iturbe. Se bautizó un 22 de enero de 1706. La copia de la partida de bautismo, de 21 de diciembre de 1732, se guarda en el Archivo Diocesano de Cádiz (ADC), Expedientes Matrimoniales, legajo 258, año 1733.

12 Carta de Francisco de Ugarte, de Aranjuez 26 de mayo de 1750 ( AGI, Caracas, legajo 144); diligencia a José de Carvajal, de Aranjuez 23 de junio de 1750 (AGI, Caracas, legajo 144); resumen del Consejo de Indias. Sin fecha, probablemente de marzo de 1763 (AGI, Caracas, legajo 145). 
a una dilatada y agotadora campaña de 12 años en Cartagena de Indias, en la que sufrió gravísimas heridas de guerra ${ }^{13}$

Ugarte fue todo un carácter; quizá su prolongada carrera militar intervino en ello. Hombre de acción, no pudo comulgar con las intrigas de la provinciana sociedad colonial; galardonado en diferentes ocasiones por arriesgar su vida, fue un incomprendido en tierra firme donde se quejaron de su genio, de su espíritu independiente y hasta del tono de su voz al hablar.

Es cierto que la personalidad del gobernador era excepcional; en los expedientes se le describe de muy diversas maneras: en unos lo encontramos en su papel de funcionario íntegro, capaz de sacrificarlo todo por sus ideales, que termina sus días empobrecido por culpa de las injustas persecuciones de sus adversarios; es la imagen que pretende mostrar de sí mismo a la Corona. Por el contrario, se le describe en otros legajos como cerebro de todas las tramas e intrigas que decía combatir; son las acusaciones que presentarán sus contrarios.

Pero es una historia complicada, que ni las mismas autoridades españolas fueron capaces de desentrañar. Sigamos hablando de sus protagonistas.

\section{FAMILIARES Y ALLEGADOS}

Con respecto a su entorno familiar, sospechamos que aunque Ugarte nunca regresó a Idiazabal, su patria chica, mantuvo una estrecha relación con sus parientes. En este sentido creemos fue responsable directo de que algunos miembros de su familia abandonaran Guipúzcoa siguiendo sus pasos; con toda probabilidad influirían de forma decisiva su brillante hoja de servicios en la marina y, más tarde, el poder que sin duda tuvo en la gobernación de Maracaibo.

Se encuentra registrado el nombre de una sobrina suya que en 1751 obtenía permiso del monarca para trasladarse a Maracaibo en compañía de su tío y sus más allegados. De ella hace la licencia de embarque una somera descripción, anotando la edad que tenía entonces (18 años), el nombre (María Vicenta de Ugarte), su estado civil (soltera) y una escueta semblanza física, puntos todos ellos de interés en una época que carecía de instrumentos más fiables para la identificación ${ }^{14}$. En documentos fechados con posterioridad, aparece otro familiar, un sobrino (Juan Antonio) del que se apunta fue objeto de desaires y vejaciones por llevar el apellido Ugarte, coincidiendo tales sucesos con momentos algo difíciles para nuestro protagonista en la provincia ${ }^{15}$. Cierra la lista de familiares vascos Pedro Ugarte, aunque desconocemos el parentesco exacto que les unía. Jugó un papel notable al convertirse en su persona de confianza, cuando se vio obligado nuestro hombre a abandonar Maracaibo de forma precipitada, siguiendo órdenes superiores, dejando sus

3 Sucedió en el cargo a Francisco Collado. Su título de gobernador está fechado en Buen Retiro el 19 de enero de 1751 (AGI, Caracas, legajo 52). Para más información acerca del bloqueo y asalto a Cartagena de Indias véase ACADEMIA COLOMBIANA DE HISTORIA, Historia extensa de Colombia. Volumen IV.- Nuevo Reino de Granada. El virreinato. Tomo 1, 1719-1753. Bogotá, Ediciones Lerner, 1970, pp. 197ss.

14 Real cédula de licencia de pase a Indias, de Buen Retiro 27 de enero de 1751 (AGI, Contratación, legajo 5493, N.2, R.9).

15 Carta de Francisco de Ugarte al gobernador y juez de las reales comisiones Antonio Guill, de Maracaibo, 26 de marzo de 1755 (AGI, Caracas, legajo 144). 
pleitos inconclusos y a Petronila, su esposa, sola y expuesta a las maquinaciones de sus contrarios, al menos en apariencia ${ }^{16}$.

Esta mujer, Petronila, merece una mención especial. Petronila de Santisteban y Zuloaga era gaditana de nacimiento. Sus primeros años transcurrieron entre Cádiz y Puerto Real. Los expedientes del Archivo Diocesano dan pistas que permiten reconstruir las circunstancias que intervinieron en su relación con Ugarte; su padre adoptivo, Carlos de Anglada fue un gran aficionado a los viajes por mar, lo que le dio oportunidad de conocer a Francisco de Ugarte en sus tiempos de marino y a disfrutar de su compañía en algunas travesías por tierras americanas. Por esta razón Ugarte, viejo amigo de la familia, se convertiría en uno de los candidatos más adecuados para desposar a Petronila. En 1733 tendría lugar el enlace, si bien bajo la modalidad de "matrimonio secreto". La documentación se limita a registrar que, a solicitud del propio Ugarte, se les eximieron de las amonestaciones prescritas, añadiéndose en nota marginal que cinco años más tarde, esto es en 1738, recibió la pareja las bendiciones nupciales. Dado que un hijo del matrimonio, de nombre también Francisco, nació a finales de aquel año de 1738, se puede sospechar que se celebró de esta manera por la premura de Francisco de Ugarte en embarcar, acomodándose a los cánones establecidos a su regreso e iniciándose entonces, de hecho, su vida marital ${ }^{17}$.

Disponemos también de una descripción física de Petronila incluida en la licencia de embarque. La nota más sobresaliente se refiere a su cara dañada por la viruela, enfermedad que no podemos precisar cuando contrajo. Parece, por otro lado, que esta mujer no gozó nunca de muy buena salud, si hacemos caso a lo que se alega con insistencia en determinados documentos; la presentan eternamente postrada en la cama y con periódicas crisis, a veces de tal gravedad que fue preciso buscar un sacerdote ${ }^{18}$. No obstante estas limitaciones de Petronila, evidentemente graves, su unión con Ugarte fue sólida; ella demostró tener una gran fortaleza y se convirtió en una de sus aliadas más importantes. Como prueba de lo que se ha dicho, puede bastar el hecho de que Petronila se convirtiera en apoderada de su marido en momentos críticos para él y que nunca se sintiera amedrentada por las presiones de las autoridades por fuertes que pudieran $\operatorname{ser}^{19}$.

De los hijos habidos del matrimonio, las referencias son escasas. Solo conocemos el nombre de uno de ellos, el ya citado Francisco, que suponemos el mayor. Tampoco es fácil concretar su número. Pensamos que su nacimiento tendría lugar entre 1738 y 1751, es

16 Carta de Rafael Nebot, Nicolás José Antúnez Pacheco, Pedro González de Acuña y Juan Antonio Rodil a Francisco de Ugarte, de Maracaibo 10 de octubre de 1767; petición de Petronila Santisteban y Zuloaga. Sin fecha, seguramente de enero de 1769. Ambos documentos en AGI, Caracas, legajo 145.

17 La partida de bautismo de Petronila Santisteban está fechada en Cádiz el 26 de febrero de 1714; se recoge en ella el nombre de sus progenitores, Diego Santisteban y Josefa Chévere (Archivo de la Catedral de Cádiz, ACC, Libros Sacramentales, Bautismos, legajo 37); "Matrimonio sigiloso de Dn. Francisco de Ugarte con Dña. Petronila Santisteban" (ADC, Expedientes Matrimoniales, legajo 258, año 1733); partida de matrimonio, de Cádiz, 29 de julio de 1733 (ACC, Libros Sacramentales, Matrimonios Secretos, legajo 2); partida de bautismo de Francisco Antonio Ugarte, de Cádiz 16 de octubre de 1738 (ACC, Libros Sacramentales, Bautismos, legajo 49).

18 Real cédula de licencia de pase a Indias, de Buen Retiro 27 de enero de 1751 (AGI, Contratación legajo 5493, N.2, R.9); solicitud de Petronila Santisteban al vicario juez eclesiástico. Sin fecha, de 1767 (AGI, Caracas legajo 145)

19 Se conocen los nombres de tres apoderados de Ugarte: Pedro de Ugarte, Petronila Santisteban y Felipe Altolaguirre; mientras los dos primeros cuidaron de los asuntos del gobernador en Maracaibo, Altolaguirre lo hizo en España. Véase representación de Francisco de Ugarte, sin fecha (posterior a marzo de 1764); petición de Petronila Santisteban, sin fecha (de enero de 1769). Los dos documentos en AGI, Caracas legajo 145. 
decir, antes del viaje del matrimonio a la gobernación de Maracaibo. Se desconoce asimismo en qué momento se fueron a América pero desde luego no lo hicieron en 1751, momento en que se autoriza a Francisco de Ugarte a efectuar el viaje a Maracaibo en compañía sólo de su mujer, su sobrina y cuatro criados ${ }^{20}$

En los papeles fechados entre 1753 y 1760 hay escuetas alusiones a sus descendientes mientras que con posterioridad se menciona que Petronila Santisteban no tiene hijos a su cargo ${ }^{21}$. Casualmente es de Francisco del único que hemos podido rastrear alguna noticia. Así, está documentado que tuvo algunas dificultades por deudas , que su padre debió saldarlas y que en este asunto, no del todo aclarado, se barajó el nombre de una mujer; incidente que no parece tuviera demasiadas consecuencias porque, algo más tarde, aparece afincado en la ciudad de Coro, después de contraer matrimonio ${ }^{22}$

Hasta aquí la saga de los Ugarte, a su lado figuran nombres de distintos personajes relacionados con la sociedad de Maracaibo.

\section{ENCUENTROS Y DESENCUENTROS EN MARACAIBO}

Empecemos nuestra relación con determinados oficiales reales destinados en la provincia. Es el caso de Antonio Guill y Gonzaga, Francisco Moreno de Mendoza o Alonso del Río y Castro que, como Ugarte, ejercieron también tareas de responsabilidad en la gobernación. Guill, el primero de ellos, estuvo al frente de una comisión formada con carácter extraordinario para investigar determinadas gestiones de Francisco de Ugarte; la gravedad de la materia motivó que debiera ser apartado del gobierno temporalmente.

Por su parte, Francisco Moreno y Alonso del Río obtuvieron el título de gobernadores de Maracaibo en 1758 y 1765, respectivamente, y su relación con Francisco de Ugarte tiene que ver con su juicio de residencia. Como sabemos, todo funcionario de la Corona debía rendir cuentas de su buena o mala gestión, una vez concluido su mandato. Se abría entonces una información donde podían declarar todos los que lo desearan en un sentido u otro; es lo que se conoce por juicio de residencia. Pero algo tan fácil de comprender en la teoría, en el caso de Ugarte fue complicado. Cansado de esperar un juicio que no llegaba, Francisco de Ugarte se desesperó; sin un nuevo destino y sin perspectivas de tenerlo en un plazo breve, Ugarte no se hallaba en ningún lugar, lo que motivaría, más de una vez, la aplicación de severas medidas pues las dificultades creadas por Ugarte llegaron al extremo de perturbar peligrosamente la tranquilidad de la propia ciudad de Maracaibo $^{23}$.

20 Aunque anecdótico, hemos podido averiguar quien trasladó a los Ugarte. Viajaron en 1751 en un navío de registro a cargo de Francisco Roldán, según declaró este mismo individuo muchos años después, el 2 de septiembre de 1767 (AGI, Caracas legajo 145).

21 Representación de Francisco de Ugarte al gobernador y juez de las reales comisiones Antonio Guill, de Maracaibo 26 de marzo de 1755 (AGI, Caracas legajo 144); representación de Ugarte. Sin fecha, de 1764 (AGI, Caracas legajo 145); carta del virrey Pedro Messía de la Cerda a Julián de Arriaga, de Santa Fe 28 de marzo de 1770 (AGI, Caracas legajo 145).

22 Francisco se vio comprometido por una pequeña deuda con una mujer, una tal Inés Fresfi, allá por 1763. Real orden a Julián de Arriaga, de Buen Retiro 7 de julio de 1763 (AGI, Caracas legajo 145). Pedro M. ARCAYA recoge el dato de la presencia de Ugarte hijo en Coro (Población de origen europeo de Coro en la época colonial. Caracas, Biblioteca de la Academia Nacional de la Historia 114, 1972, p. 324.

23 Carta de Francisco de Ugarte al gobernador y juez de las reales comisiones Antonio Guill, de Maracaibo 26 de marzo de 1755 (AGI, Caracas legajo 144); carta de Antonio Guill, de Coro 15 de octubre de 1755 (AGI, Caracas legajo 144); resumen del Consejo de Indias de diferentes documentos relativos a Francisco de Ugarte. Sin fecha, 
Reseñar, por último, dos nombres más de personas vinculadas a la realidad marabina, por ceñirnos a los más significativos. Felipe Miguel de Iriarte y José Armesto fueron estrechos colaboradores de Ugarte o, al menos, debían haberlo sido. Iriarte era la persona, en principio, más próxima a Ugarte, su teniente, aunque desde bien pronto sus relaciones fueron tensas y su cooperación nula. José Armesto, por su parte, era tesorero de las Cajas Reales.

Es difícil explicar en pocas palabras la razón de sus desencuentros, que fueron muchos: quizá residía en el talante un tanto autoritario de Francisco Ugarte, como denunciaban sus adversarios; quizá, tal vez, en la incompetencia y venalidad de los funcionarios locales, ligados estrechamente por intereses económicos a los sectores más pudientes de la ciudad de Maracaibo, como en repetidas ocasiones denunció nuestro hombre. Con independencia de lo que creamos, el hecho es que sus tensiones no fueron diferencias puntuales sino que derivaron en una enemistad que fue creciendo a lo largo de los años ${ }^{24}$.

No todo se reducía, sin embargo, a Maracaibo. A lo largo de los casi veinte años en que el destino de Ugarte estuvo unido a la provincia (1751-1770), se sucedieron al frente del virreinato de Nueva Granada, en el que estaba integrada la gobernación, diferentes mandatarios. Todos ellos tuvieron que ver de una forma u otra con las ajetreadas peripecias de Francisco de Ugarte.

\section{SANTA FE Y LOS VIRREYES}

Tres son los virreyes de los que debemos hacer mención: José Alfonso Pizarro, marqués de Villar (1749-1753), José de Solis Folch de Cardona, duque de Montellano (17531761) y, por último, Pedro Messía de la Cerda, marqués de la Vega de Armijo (1761-1773). Las relaciones de Ugarte con el primero de lo vicesoberanos citado fueron enormemente fluidas; Francisco de Ugarte llegó a afirmar que sus éxitos iniciales en Maracaibo obedecieron a su buen entendimiento con Santa Fe de Bogotá, si bien invariablemente añadía que con los sucesores de Pizarro la realidad fue otra bien distinta.

En efecto, Solis y Messía tuvieron una política diferente con respecto a Maracaibo. Mientras, al parecer, Pizarro, confió en el buen criterio de Ugarte y le dejó hacer, sus sucesores imprimieron un nuevo giro a su gestión preocupándose por centralizar desde Santa Fe todos los asuntos, incluidos los de Maracaibo. Esta nueva filosofía de los gobernantes de Bogotá no fue aceptada demasiado bien en la gobernación -acostumbrada a ser autónoma- y tampoco por Ugarte, lo que llevó a continuos enfrentamientos.

De otra parte, conocedores los enemigos de Francisco de Ugarte de sus tirantes relaciones con Bogotá, se aprovecharon de ello. De esta suerte, hicieron llegar sus protestas con relativa frecuencia a Santa Fe, con la casi seguridad de que serían escuchadas; por la

en torno a marzo de 1763 (AGI, Caracas legajo 145); representación de Ugarte. Sin fecha, de 1764 (AGI, Caracas legajo 145); carta de Ugarte a Julián de Arriaga, de Madrid, 21 de agosto de 1769 (AGI, Caracas legajo 145); memorial de Francisco Ugarte al monarca. Sin fecha, probablemente de 1770 (AGI, Caracas legajo 145). Véase, Ligia BERBESÍ DE SALAZAR y Belín VÁZQUEZ DE FERRER, "Juicios de residencia en el gobierno provincial de Maracaibo, 1765-1810". En Anuario de Estudios Americanos, Sevilla LVII-2, julio-diciembre 2000

24 Carta de Francisco de Ugarte al marqués de la Ensenada, de Maracaibo 19 de marzo de 1753 (AGI, Caracas legajo 146); carta de José Armesto de Sotomayor al marqués de la Ensenada, de Maracaibo 17 de abril de 1753 (AGI, Caracas legajo 146); real orden a Antonio Guill, de Madrid 7 de febrero de 1754 (AGI, Caracas legajo 144); carta de Francisco Ugarte, de Maracaibo 9 de noviembre de 1754 (AGI, Caracas legajo 144). 
misma razón en situaciones de especial gravedad para ellos, buscaron refugio en la capital del virreinato.

Los problemas de nuestro protagonista, ya de por sí importantes, se veían de esta forma automáticamente agrandados ${ }^{25}$.

\section{LA AGITADA HISTORIA DE FRANCISCO DE UGARTE}

Pasemos a otro punto. En los hechos que vamos a analizar se distinguen dos periodos, de aproximadamente diez años cada uno. El primero, 1751-1762, supone para Ugarte el descubrimiento de Maracaibo en muchos sentidos: es el inicio, con bastante brío por cierto, de su gestión, también de sus primeras dificultades con otros representantes de la Corona. Para su sorpresa advertirá, poco tiempo después de su llegada, que era menos complicado mantener el timón firme en mar abierto que navegar por los turbios riachuelos de la burocracia indiana.

El segundo periodo, que se extendería de 1762 a 1770, es una etapa donde todo es exagerado: las relaciones de Ugarte con el poder no pueden ser más crispadas; los intentos por serenar los ánimos de algunos que se llaman mediadores rozan el esperpento. Los días de gloria de Francisco de Ugarte, en definitiva, están contados, probablemente a causa de todos estos excesos.

\subsection{Primera etapa, 1751-1762}

Ugarte gobernó siete años Maracaibo, de 1751 a 1758. Su mandato estuvo lleno de sobresaltos y, una vez concluido, hubo de permanecer más tiempo del habitual en la ciudad, en un ambiente hostil, esperando un juicio de residencia que se dilataba, hasta que por último intervino la Corona.

Sus comienzos en la provincia, sin embargo, habían sido diferentes. Llegó a la gobernación a mediados de 1751 y, casi de inmediato, dictó medidas dirigidas a sacar Maracaibo de su letargo: contagiado de la política renovadora borbónica, plantó cara a los problemas de la provincia. Con relativo éxito, gracias a drásticas medidas que resultarían a la fuerza impopulares, saneó la Real Hacienda y la liberó de corruptelas, generando más ingresos, hasta el punto de que ya no fue necesaria la ayuda del situado que llegaba a la provincia con regularidad procedente de Caracas y Santa Fe. También por estos años se fecha el cobro de nuevos impuestos, como el que lleva el curioso nombre de "alcabala del viento".

25 Escrito de Antonio Guill al virrey José de Solís, de Maracaibo 20 de junio de 1755 (AGI, Caracas legajo 144); representación de Francisco de Ugarte. Sin fecha, posterior a marzo de 1764 (AGI, Caracas legajo 145); carta de Pedro Messía de la Cerda a Julián de Arriaga, Santa Fe 23 de julio de 1767 (AGI, Caracas legajo 145); petición de Petronila Santisteban y Zuloaga. Sin fecha, de enero de 1769 (AGI, Caracas legajo 145); otra carta de Messía de la Cerda a Arriaga, de Santa Fe 28 de marzo de 1770 (AGI, Caracas legajo 145). Pueden consultarse en este sentido las obras de José Antonio GARCÍA Y GARCÍA (Relaciones de los virreyes del Nuevo Reino de Granada ahora Estados Unidos de Venezuela, Estados Unidos de Colombia y Ecuador. Compiladas y publicadas por el Sr. Dr. D. —_. Nueva York, Imprenta de Hallet and Breen, 1869, pp. 1-109) y Gabriel GIRALDO JARAMILLO (Relaciones de mando de los virreyes de la Nueva Granada. Memorias económicas. Edición preparada por - . Bogotá, Publicaciones del Banco de la República. Archivo de la Economía Nacional, 1954, pp. 43 ss.). 
De igual manera, puso todo su empeño en frenar el contrabando, práctica habitual en la región con el consentimiento más o menos tácito de los funcionarios de la monarquía ${ }^{26}$.

Se decidió a intervenir también en el problema de los indios motilones, causantes de una importante inestabilidad en la región. Elaboraría, en este sentido, un plan estratégico para reducirlos por las armas, aunque él prefirió denominarlo "proyecto", apuntándose a la moda de un género literario que tuvo vigencia en el mundo hispánico en los siglos XVII y XVIII. No mucho después de su desembarco en la gobernación, mandó en este sentido a Ensenada un curioso "Proyecto para que se pueda conseguir la extinción de aquellos bárbaros" donde apuntaba todos los pormenores precisos sobre el número de soldados necesario, así como lo relativo al plan a seguir. Básicamente su propuesta se resumía en establecer un cerco cada vez más estrecho a estos indios hasta reducirlos por completo.

No se tiene noticia de la acogida que tuvieron en la península sus ideas, tampoco Ugarte vuelve a mencionarlas; quizá se puede pensar que con el paso del tiempo las reconsideró, en parte gracias a su mejor conocimiento de la realidad de la región, pues en algunos expedientes de fecha posterior se aprecia un tono diferente al hablar de la población indígena en términos generales ${ }^{27}$.

Francisco de Ugarte no tuvo miedo de intervenir en un asunto delicado de consecuencias imprevisibles: el de los enfrentamientos entre las gentes supuestamente más "respetables" de la provincia. Con estas miras centraría todo su interés en Barinas, a raíz de unos gravísimos acontecimientos que habían terminado con la vida de varios oficiales reales.

"Para satisfacer a este soberano precepto pongo en la elevada mente de V.E. que con la primera noticia que tuve en principios de Mayo de el año de 754 de las tres muertes sucedidas en el Alcalde Provincial Dn. Joseph de el Pumar por dn. Antonio de Uzcategui teniente de gobernador que fue de aquella jurisdicción y la de este por el Alcalde de la hermandad dn. Ambrosio Moreno que por la alevosía cometida en el expresado Pumar, y por motivos de haber levantado gente, y puesto horca, y Banquillo en la Plaza sin Jurisdicción para ello respecto de haber hecho fuga de aquella ciudad y pasado a Santa Fee..."28.

Estas medidas del gobernador, quizá por la forma de llevarlas a cabo -Ugarte, como hombre curtido en la guerra, gustaba poco de la diplomacia-, quizá porque, en última ins-

26 Representación del coronel Francisco de Ugarte al rey. Sin fecha, posterior a 1758 (AGI, Caracas legajo 144); otra representación de Ugarte. Sin fecha, en torno a 1764 (AGI, Caracas legajo 145). Según la profesora María José NESTARES PLEGUEZUELO, que ha estudiado la alcabala del viento en el Oriente Venezolano, debían abonarla los forasteros que deseaban vender sus géneros -léase comestibles, fundamentalmente- en la ciudad (Fiscalidady marginalidad en el Oriente Venezolano. Almería, Universidad, 1999, p. 70). Véase también la monografía de Montserrat FERNÁNDEZ MARTÍNEZ, La alcabala en la Audiencia de Quito, 1765-1810. Cuenca, Ecuador, 1984, p.95.

27 Carta de Ugarte al marqués de Ensenada adjuntando proyecto, de Maracaibo 8 de noviembre de 1753 (AGI, Caracas 144). Para la comprensión de este tipo de escritos sigue teniendo vigencia el trabajo de José MUÑOZ PÉREZ, “Los proyectos sobre España e Indias en el siglo XVIII: El proyectismo como género". En Revista de Estudios Políticos ,82 (1955), Madrid. Yo misma realicé algunos trabajos sobre este tema, en los inicios de mi carrera universitaria, como mi propia tesis doctoral; véase Proyectismo y minería en Perú, 1775-1821. Granada, Universidad, 1985.

28 Carta de Ugarte a Julián de Arriaga, de Maracaibo 26 de febrero de 1756 (AGI, Caracas legajo 144). 
tancia, beneficiaban en exclusiva a los intereses de la Corona, fueron contestadas en muchos sectores. Este malestar se acentuó a partir de un determinado momento.

\subsubsection{Un gobernador en dificultades}

En 1753, tras dos años escasos en Maracaibo, empiezan los contratiempos. Coincide con cambios en el virreinato de Nueva Granada; sucede a José Alfonso Pizarro al frente del mismo José de Solis Folch, lo que se acompaña de una nueva forma de afrontar los entresijos de la política. Se advierte, a partir de esta fecha, un interés explícito por conocer de los asuntos de Maracaibo. La respuesta de Francisco Ugarte no se hará esperar: lejos de cooperar, se documenta una postura de rechazo sistemático a los mandatos procedentes de Nueva Granada. A este panorama que describimos, ya de por sí complicado, se une la estrategia de los enemigos de Ugarte que aprovecharán estas tensas relaciones con el virreinato en beneficio de sus intereses.

A partir de entonces, el gobernador será controlado cada vez más estrechamente desde Bogotá; se intentarán recortar sus competencias y, al resistirse, se llegará a un enfrentamiento en toda regla. Será la excusa el nada claro asunto de Barinas. Los dramáticos sucesos ocurridos en esta ciudad se verán oscurecidos al anteponerse meras cuestiones de forma. Las diferentes autoridades discutirán no sobre lo fundamental -la necesidad de nombrar una comisión para investigar lo ocurrido- sino sobre lo accesorio -a qué mandatario le competía su designación-. Cada parte defenderá una propuesta distinta hasta sus últimas consecuencias; Bogotá elegirá para ello a Felipe Iriarte mientras que Ugarte, automáticamente, lo suspenderá y en su lugar pensará en Gaspar Vanhemert para el puesto $^{29}$

La historia continúa en un momento en que las relaciones Maracaibo-Santa Fe están rotas, se ha retirado momentáneamente a Ugarte de la gobernación y en su lugar se ha nombrado a Antonio Guill. Este juez pesquisidor y gobernador interino abrirá una información para esclarecer los hechos y la legitimidad o no de las demandas que esgrimen las diferentes partes. También es el momento de escuchar a los presuntamente perjudicados por Ugarte durante su, breve gobierno. Entre los nombres de los denunciantes figuran Iriarte y Armesto $^{30}$.

Guill debe responder además a las presiones del virrey y la Audiencia, partidarios de aplicar al gobernador suspendido otras medidas más drásticas. Guill trata de mantener un difícil equilibrio: acatar los mandatos superiores que proceden de Bogotá y mantener intactos, al mismo tiempo, sus legítimos derechos como gobernador interino; de esta delicada posición informará primero a Caracas y, después, a la propia península ${ }^{31}$.

Otro problema que causará al comisionado no pocos quebraderos de cabeza concierne al propio Ugarte; su peculiar carácter dificultará el acercamiento entre los dos personajes. Francisco de Ugarte se siente acosado por supuestos enemigos que ve por todas partes y así se lo hace saber al comisionado, unas veces de buenas maneras pero otras,

29 Real acuerdo, de Santa Fe 10 de enero de 1754; carta de Ugarte al monarca, de Maracaibo 9 de noviembre de 1754. Los dos documentos en AGI, Caracas legajo 144.

30 Petición de Felipe de Iriarte, de Maracaibo 6 de noviembre de 1754 (AGI, Caracas legajo 144).

31 Carta de Antonio Guill a Julián de Arriaga, de Maracaibo 9 de agosto de 1755 (AGI, Caracas legajo 144). 
claramente no. En 1755 se quejaba el comisionado de lo "violento de su genio y travesura":

“... como la experiencia ha dado tanta prueba en lo violento de su genio, y travezura, de que dio muestras bien públicas (aún con estar yo aquí Comisionado por S.M.) pues en esta Semana Santa con sólo el motivo de un lance entre su sobrino, y el Teniente de la Compañía del Presidio Dn. Joséph Antonio Sánchez, sobre si en lugar de corresponderle a quitarle el sombrero, le había vuelto la espalda (que todo se justificó incierto) me pidió primero con un Ayudante, y después con el citado Sobrino, se le hiciese justicia, y diese satisfacción a él; y respondiéndole yo con ambos, como testigos de la información, que por ella no tenía arbitrio para complacerle, se dejó llevar tanto de el ardor de sus ímpetus que prorrumpió en las más desordenadas voces, que se oyeron en toda la plaza, como un hombre fuera de sí, presentándome luego un escrito en los términos más mordicantes contra lo puro de mi conducta..." 32 .

\subsubsection{Ugarte y las autoridades peninsulares}

Otro momento de esta agitada historia se fecha en 1755, en el que llegan desde Madrid disposiciones en el sentido de que Ugarte fuera restablecido en su cargo. La Corona renovaba así la confianza puesta en él y en su política, al menos mientras le fuera de utilidad.

La comisión extraordinaria de Antonio Guill se da por concluida. Sin embargo, esta resolución sólo en apariencia puso fin a las dificultades de Ugarte en la provincia. Cierto que de nuevo ejerció las tareas de gobernador-desde ese año hasta el de 1758 - $^{33}$, pero su adversarios permanecieron y, con ellos, sus intrigas. Sabemos, eso sí, que cayeron temporalmente en desgracia.

Iriarte había logrado, aunque sólo de forma momentánea, encabezar la comisión destinada a Barinas, pero eso fue origen de conflictos aún mayores, como había pronosticado Ugarte; fue sustituido por esta razón con celeridad y se optó por el candidato elegido en su momento por Francisco de Ugarte. En parte se encuentra documentado también el resultado de las protestas de José Armesto, oficial de las Cajas Reales de Maracaibo, sobre el modo autoritario de proceder de Ugarte a la hora de controlar los caudales de la Real Hacienda; se sabe, al respecto, que fue alejado de sus funciones con carácter temporal ${ }^{34}$.

Pero insisto, esta victoria de Francisco de Ugarte fue sólo temporal. En 1758, la llegada de un nuevo gobernador-Francisco Moreno de Mendoza-supuso, ante todo, una oportunidad para sus adversarios.

32 Escrito de Antonio Guill al virrey José de Solis, de Maracaibo 20 de junio de 1755 (AGI, Caracas legajo 144).

33 Ugarte tomó posesión por segunda vez el 14 de septiembre de 1755. Véase, escrito de Antonio Guill a Julián de Arriaga, de Maracaibo 10 de septiembre de 1755; resumen del Consejo de Indias de otra carta de Guill de la misma fecha; otra carta suya fechada en Coro el 15 de octubre de 1755. Estos documentos en AGI, Caracas legajo 144.

34 Carta de Ugarte a Julián de Arriaga, de Madrid 22 de diciembre de 1762 (AGI, Caracas legajo 145). 
Obligado Ugarte a permanecer en la ciudad, como establecían las leyes, hasta la celebración de su juicio de residencia, fue objeto de presiones, aprovechando que su posición ya no era tan ventajosa. Bien sea por su fuerte personalidad -a la que hacemos con frecuencia alusión-, bien sea por las argucias de sus adversarios políticos, las relaciones entre los dos gobernadores -el saliente y el nuevo- se tornaron cada vez más frías. Durante los cuatro años que median entre 1758 y 1762, se documenta una situación de deterioro progresivo; Ugarte llegó a ser perseguido literalmente, sufriendo privación de libertad y repetidos embargos de bienes, que él se ocupó de describir y, quizás, exagerar, de forma bastante elocuente:

“... Fuele nombrado por sucesor Dn. Francisco Moreno con quien usó de las mayores atenciones y su mujer con la de aquel, pero a estímulos del tesorero de aquellas Cajas y con el dispendio de 2000 doblones... empezó a tirarle por los medios más escandalosos; sufrió tres prisiones, y el refugio de cuatro meses y medio sin autoridad alguna, ni otro motivo que el de su antojo; habiéndole hecho 5 embargos de bienes, y vendidole en el último todos sus muebles, hasta la olla, en que estaba la comida del dia..." ${ }^{35}$.

A finales de 1760, las preocupantes noticias que llegan de Maracaibo determinan una nueva intervención de las autoridades peninsulares. Alarmaba el enfrentamiento público entre los dos oficiales del rey, sobre todo por la repercusión que estaba teniendo en la sociedad, cuestión de indudable importancia en la época. Se ordena el retorno inmediato de Ugarte, si bien dificultades de última hora, no se sabe si intencionadas o no, lo dilatan cerca de dos años ${ }^{36}$.

Cierra esta primera etapa la partida de Francisco Ugarte. No hay despedidas ni agasajos para el que fuera gobernador, aunque en tan apasionante historia quedan páginas por abrir.

\subsection{Segunda etapa, 1762-1770}

Una de sus características es que se desarrollará en diferentes escenarios. Se inicia en Madrid (1762-1765), en donde básicamente el objetivo de Ugarte es justificar y convencer. Debe explicar a sus protectores -fundamentalmente a Ensenada- su versión de todo

35 Representación de Francisco de Ugarte. Sin fecha, posterior a marzo de 1764 (AGI, Caracas legajo 145).

36 La real cédula comunicando la decisión del monarca está fechada el 27 de noviembre de 1760, Ugarte la presentó en el Cabildo el 30 de marzo de1761, aunque no embarcó en el Puerto de La Guaira hasta el 9 de junio del siguiente año. Véase, real cédula de Buen Retiro de 27 de noviembre de 1760; acuerdo del cabildo de Maracaibo, de Maracaibo 31 de marzo de 1761; carta de Francisco de Ugarte a Julián de Arriaga, de Madrid 22 de agosto de 1762. Estos documentos en AGI, Caracas legajo 145. Según cánones preestablecidos, la importancia o no de determinados acontecimientos estaba muchas veces en función de la trascendencia social que hubieran tenido; véase, GONZÁLEZ MARMOLEJO, Jorge René, "Lo malo no es el pecado sino el escándalo. Un caso de adulterio en la ciudad de México, siglo XVIII”. En Dolores ENCISO, Jorge René GONZÁLEZ MARMOLEJO y otros, Senderos de palabras y silencios. Formas de comunicación en la Nueva España. Seminario de historia de las mentalidades. México, Instituto Nacional de Antropología e Historia, 99-112, 2000. 
lo ocurrido; se presentará para la ocasión como víctima de las irregularidades de aquellos funcionarios corrompidos. Sospecho que estas maniobras del antiguo gobernador tuvieron el resultado apetecido, pues data de entonces una consulta del Consejo de Indias favorable a nuestro personaje, hasta el punto de recomendarlo al monarca para que le diera un nuevo destino.

Pero, pasado un tiempo prudencial, también ha de persuadir Ugarte de la conveniencia de retornar a Maracaibo, una vez recuperado el favor de los poderosos. Allí, al fin, va a tener lugar su juicio de residencia y él desea, como parte directamente interesada, estar presente. En su precipitada marcha, por otro lado, se vio en la necesidad de dejar en la gobernación a su familia, razón de más para pensar en volver. Precisamente en estos años finales de la historia, su esposa Petronila merecerá una mención especial ${ }^{37}$.

En la primavera de 1765 Ugarte ve cumplido su deseo de viajar a Maracaibo; no obstante, los hechos demostrarían que sería perjudicial para sus intereses hasta el punto de dañarlos irremediablemente ${ }^{38}$.

En esta corta estancia en la gobernación (1765-1768), Ugarte encuentra novedades: hay otro gobernador, Alonso del Río, y un nuevo mandatario en Bogotá de nombre Pedro Messía de la Cerda. Sin embargo, este panorama es nuevo solo en apariencia: permanecen las mismas fracturas y el retorno de Francisco de Ugarte, en este sentido, no hace sino agrandarlas.

Por otra parte, el juicio de residencia es más complejo de lo imaginado, pues tienen lugar no uno sino tres juicios simultáneos. Corresponden uno a Ugarte, otro a su antecesor en el cargo, Francisco Collado, y finalmente, el tercero a su sucesor Moreno de Mendoza. Esto motivó un recrudecimiento, casi inmediato, de las anteriores tensiones; los problemas entre los diferentes mandatarios, por otra parte, se hicieron extensivos a la ciudad que sufrió, en consecuencia, una peligrosa desestabilización.

Alonso del Río, desconcertado ante estos acontecimientos y consciente de la imposibilidad de poner freno a tanto descontrol, pensará en una novena como fórmula milagrosa -nunca mejor empleada esta palabra- para apaciguarlos. Obsérvese que, en pleno Siglo de las Luces, se contempla aún la idoneidad de soluciones de este tipo.

“... consideré precisa alguna providencia cristiana para que llamando la atención de los oyentes, se viese a lo menos en el público alguna disposición a la tranquilidad; y valiéndome de el motivo de la novena de San Francisco Javier se dispuso en ella una seria misión por el superior y padres jesuitas de la residencia que tienen en esta ciudad, después de la que, ya tenía algunas esperanzas de conseguir el fin de mi solicitud..." 39.

El virrey Messía de la Cerda se inclinará por medidas más pragmáticas; así, reviviendo políticas de quienes le precedieron en el cargo, dispuso que las partes en litigio debían

Resumen del Consejo de diferentes documentos relativos a Francisco de Ugarte. Sin fecha, de marzo de 1763; consulta del Consejo de 28 de mayo de 1763; representación de Ugarte. Sin fecha, de 1764. Estos documentos en AGI, Caracas legajo 145 .

38 Llegó con anterioridad a agosto de 1765. Carta de Alonso del Río al virrey Messía de la Cerda, de Maracaibo 22 de agosto de 1765 (AGI, Caracas legajo 145).

39 Carta del gobernador Alonso del Río a Julián de Arriaga, de Maracaibo 5 de septiembre de 1765 (AGI, Caracas legajo 145). 
abandonar de inmediato la ciudad mientras esperaban su correspondiente sentencia al juicio de residencia, si bien fue especialmente contundente con Ugarte ${ }^{40}$.

Francisco de Ugarte, muy a su pesar, se vio forzado a abandonar de nuevo Maracaibo en circunstancias extraordinarias. Dejará, eso sí, a su esposa Petronila para que defienda sus intereses, violando la orden de destierro dictada.

Nuestro viejo gobernador depositará en Petronila sus últimas esperanzas. Su objetivo era bastante claro, utilizarla como comodín para mantener sus alianzas y, en última instancia, su parcela de poder; moldeará para ello una imagen de Petronila Santisteban acorde a sus intereses. En aras de justificar su permanencia en la provincia, desoyendo el mandato de alejamiento, presentará a su mujer presa de una gravísima enfermedad, lo que la obliga a quedar en la gobernación, a su pesar. Refieren sus cartas, en este sentido, cómo se produjo la separación de los esposos. Con hábil pluma de dramaturgo, Ugarte describe con minuciosidad los espantosos vómitos de sangre de Petronila, cuya gravedad había llegado a aconsejar la administración de los santos sacramentos. Pero la historia que construye Ugarte continua con más datos, pues en ella aparece Petronila abandonada en una playa desierta, después de ser bajada con celeridad del navío, donde se tenía por cierta su muerte de continuar viaje por mar.

A pesar de las lógicas reticencias de las autoridades ante estas maniobras del gobernador Ugarte, Petronila logró quedarse en tierras marabinas. De la documentación se deduce que sobradamente cumplió las expectativas que había depositado en ella Ugarte. Haciendo caso omiso de las presiones de los funcionarios locales, actuó con total libertad, liderando el círculo de amigos fieles a Ugarte. Como prueba de todo lo dicho, hemos seleccionado un texto en que mide sus fuerzas con el mismísimo gobernador Alonso del Río.

..."El día veinte y siete de enero salí de Casigua con mi familia... entré en los Puertos la noche del día veinte y nueve muy quebrantada porque traía fríos y calenturas, el Dr. Almarza estaba de teniente le pedí mil atenciones al instante me vino a ver y le escribió al gobernador cómo yo había llegado y que venía tan enferma que daba compasión verme la respuesta de esta carta fue que inmediatamente me hiciere saber que desocupara la provincia y que sentiría mucho que yo le diera lugar a que pasara a otras cosas por la orden que tenía de V.E. el Dr. Almarza hasta lloró al hacerme saber la orden que era del cuatro de febrero, pero yo aunque interiormente estaba quemada le respondí; que para tener miedo a el coco de las amenazas que me ponía ya era grande; que me hicieran saber por qué era el destierro, y que no pensara en que yo iría a Maracaibo mientras el mandara..." 41

No obstante la fortaleza de la gaditana Petronila Santisteban, la suerte no acompañó a Francisco de Ugarte. En 1768, Ugarte ya está en Madrid. Sus aventuras, aunque él se em-

$40 \quad$ Dos cartas del virrey Messía de la Cerda a Julián de Arriaga, de Santa Fe 31 de julio de 1766 y 23 de julio de 1767 (AGI, Caracas legajo 145).

41 Certificación del escribano Miguel Francisco González de algunos párrafos de una carta de Petronila Santisteban y Zuloaga a Francisco de Ugarte, fechada en la villa de Madrid el 16 de agosto de 1768 (AGI, Caracas legajo 145) 
peña en no saberlo, han finalizado. Ha perdido muchas cosas, fundamentalmente el favor de sus mecenas que ya no lo quieren recibir y, menos, escuchar sus repetitivos alegatos.

A lo largo de los dos últimos años solicitará con tono de queja un nuevo destino-Puerto Cabello, Santo Domingo, incluso de nuevo la gobernación de Maracaibo que sabe próxima a vacar-. Ugarte ha perdido ya todas sus influencias. A pesar de que la sentencia de su juicio de residencia le fue favorable, su suerte había cambiado irremediablemente ${ }^{42}$.

\section{CONCLUYENDO}

El análisis de estos años de la vida de Ugarte ha permitido hacer un recorrido por la gobernación de Maracaibo y sus problemas. La provincia se enfrentaba, nunca mejor empleado este verbo, a una etapa de cambios, a una nueva política de inspiración ilustrada, que pretendía un gobierno más efectivo, a la vez que un mayor aprovechamiento económico.

Su realización topó con obstáculos importantes a corto y medio plazo. El propio estancamiento económico de la zona, la débil presencia de las instituciones y la resistencia latente de la misma población figuran entre los factores más significativos.

En este escenario transcurrió la historia de Francisco de Ugarte que se vio sacudido por las turbulencias de esta época de transición, unas veces como protagonista y, la mayoría como víctima.

42 Carta de Ugarte, de Aranjuez 19 de abril de 1769; memorial de Ugarte de 12 de junio de 1769; carta de Ugarte a Julián de Arriaga, de Madrid 21 de agosto de 1769; otro memorial de Ugarte. Sin fecha, probablemente de 1770. Todos estos documentos en AGI, Caracas legajo 145. 